\title{
An Exploration of COMMUNiCATION AND KNOWLEDGE APPLICATION IN MULTIDISCIPLINARY UNDERGRADUATE Engineering CAPSTONe Design TeAMS
}

\author{
Mario Milicevic, Narges Balouchestani Asli, Deborah Tihanyi, and Kamran Behdinan. \\ University of Toronto \\ mario.milicevic@utoronto.ca, narges.balouchestaniasli@mail.utoronto.ca, \\ deborah.tihanyi@utoronto.ca, behdinan@mie.utoronto.ca
}

\begin{abstract}
Multidisciplinary capstone design projects offer students the opportunity to solve complex engineering problems that span multiple disciplines through collaborative, team-based learning. Using a mixed quantitative and qualitative approach, this study examines student experience in a multidisciplinary capstone design course by analyzing how disciplinary knowledge is applied, taught, and learned among team members. Our preliminary findings suggest correlations between open communication, sharing of disciplinary knowledge, and the likelihood of taking design risks. Future work will further explore the reasons behind these correlations.
\end{abstract}

Keywords: multidisciplinary, capstone design project, undergraduate, communication, knowledge transfer, team.

\section{INTRODUCTION}

Undergraduate engineering capstone design courses allow students to infuse practical design experience into their theory-based education by working in teams to design, build, and test proof-of-concept systems. In traditional monodisciplinary design courses, students work in small teams with members from the same engineering discipline to design solutions to problems typically constrained to a single focus area. Including a multidisciplinary element to capstone design, however, offers an experience closer to engineering in the real world, where engineers typically collaborate with professionals with diverse backgrounds $[1,2]$.

A multidisciplinary capstone engineering design course, APS490, was introduced in 2013/2014 in the Faculty of Applied Science and Engineering at the University of Toronto [3]. Expanding on existing monodisciplinary capstone design courses already partnered with industry clients, APS490 seeks to expose students to the broader technical and non-technical challenges of working in teams with members from different disciplines. This approach affords the unique opportunity to expand engineering knowledge and skills beyond a single discipline, foster a professional relationship with a high-profile industry client, and collaborate with teammates to tackle complex and contemporary design challenges that span multiple engineering disciplines, which this year included aerospace, health, finance, defence, manufacturing, and education.

Key learning objectives of the multidisciplinary design course include: (1) planning, executing, and contributing to a complete team-based engineering design project, (2) reconciling conflicting perspectives and approaches, and (3) correctly applying engineering tools and principles learned in courses and through self-study. To realize their final prototype, teams must exercise appropriate judgement in integrating economic, health, safety, environment, social, and other interdisciplinary factors into their design. In this way, the course addresses and integrates multiple Canadian Engineering Accreditation Board (CEAB) graduate attributes and mirrors such initiatives at other institutions worldwide [1, 4-6].

There is some quantitative evidence, which shows that including a multidisciplinary element in capstone design produces superior technical and non-technical results when compared to their monodisciplinary counterparts [2]. However, as Hotaling et al. point out in their 2012 study [2], there is a need for further exploration of how and why these results occur.

In APS490, an initial survey of students done in conjunction with a workshop on teamwork and communication in November, 2014, indicated that teams that had set up regular meetings, scheduled design deliverables, and communicated openly with their client, supervisor, and team members seemed to have made substantially more progress in their design from the outset, in comparison to teams with weaker communication. Indeed, these findings highlight the importance of communication among disciplines to team achievement that has been discussed elsewhere [7-11]. 
These initial findings encouraged us to examine the nature of communication between disciplines happening in the teams more closely. In particular, we wondered how the transfer of knowledge between disciplines contributed to the successful completion of engineering work. While the transfer of engineering and science knowledge to design work has been examined [12,13], it has mostly been within the context of individual students' application of learning. Here, we had an opportunity to look at knowledge transfer between students.

In 2014/2015, APS490 included 83 fourth-year undergraduate students from Chemical, Electrical, Computer, Engineering Science, Mechanical, Industrial, and Materials Science engineering disciplines. As shown in Fig. 1, the goal of each project is the integration of multiple design modules from different disciplines into a single engineering design. Students working on individual modules apply their own disciplinary knowledge - often with help from another teammate in that discipline. However, work on these modules cannot occur in isolation. The construction of individual modules and their integration with others necessitates teaching and learning through cross-disciplinary communication.

This study explores the impact of communication on team dynamics, knowledge transfer, and application in multidisciplinary capstone design projects by analyzing how students apply, teach, and learn knowledge across disciplines. Specifically, through a mixed quantitative and qualitative approach, we investigate the methods and techniques that students use to: (1) apply knowledge from their own engineering discipline, (2) teach disciplinary knowledge to team members from other disciplines, and (3) learn key concepts from other disciplines relevant to the design project. Furthermore, with this study, we attempt to provide preliminary insight into how multidisciplinary team dynamics and communication influence creative design and risk-taking, and thus contribute to a more nuanced understanding of the multidisciplinary elements in engineering education.

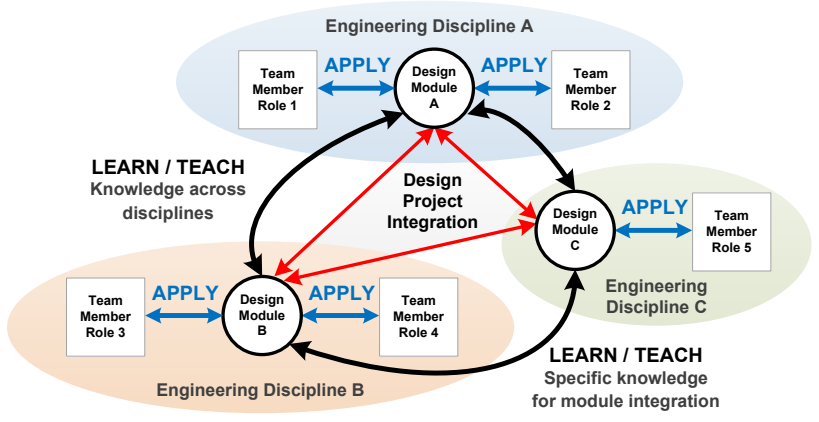

Fig. 1. Knowledge transfer dynamics in multidisciplinary capstone design teams

\section{STUDY OVERVIEW}

This study was conducted using an anonymous online survey and in-person interviews with individual students in APS490. We gathered data on how teams share knowledge among members from different disciplines and how their communication affects team dynamics.

In 2014/2015, APS490 was comprised of 20 design teams from 6 engineering disciplines. As shown in Fig. 2, each team includes students from at least two disciplines, although teams may include multiple students from a single discipline, depending on the needs of the project.

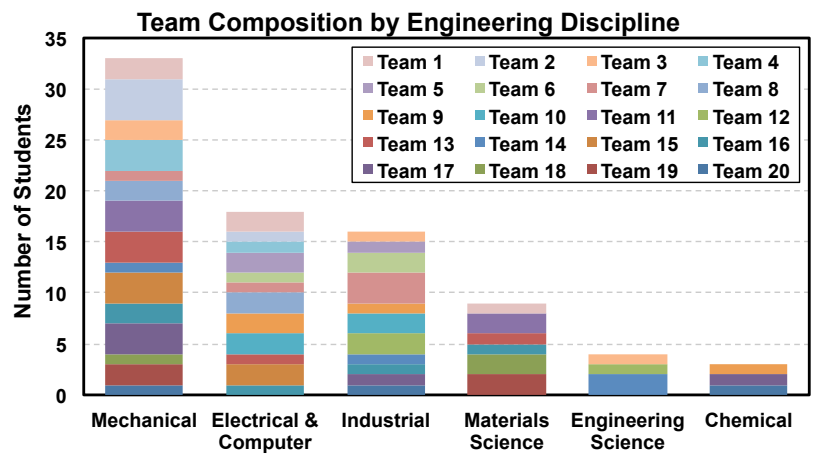

Fig. 2. Team composition of the $2014 / 2015$ APS490 class

The statistical data presented in this paper was collected from the anonymous online survey, which was completed by 46 out of the 83 students in the course, for a response rate of $55 \%$. The survey included a combination of open and closed questions, including short answer responses, Likert scale ratings, and yes/no-type questions. One-on-one interviews were conducted with 11 students in the course, who volunteered to answer a set of openended questions and discuss their multidisciplinary capstone design experience. The information collected from each 30-minute interview was used to support the findings and insights from the survey. Figure 3 presents the composition of students who participated in the study.

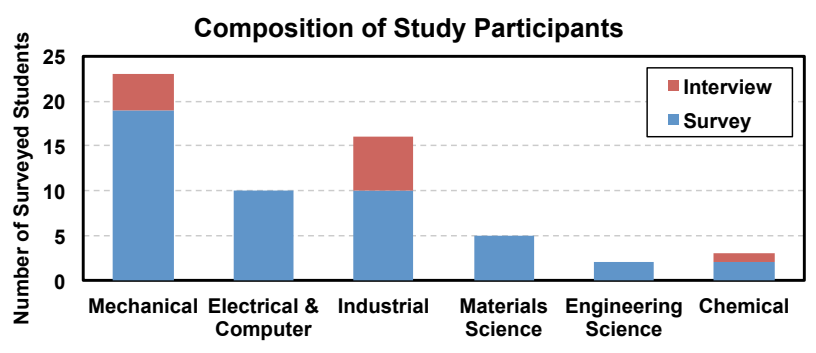

Fig. 3. Study participants from 2014/2015 APS490 class 


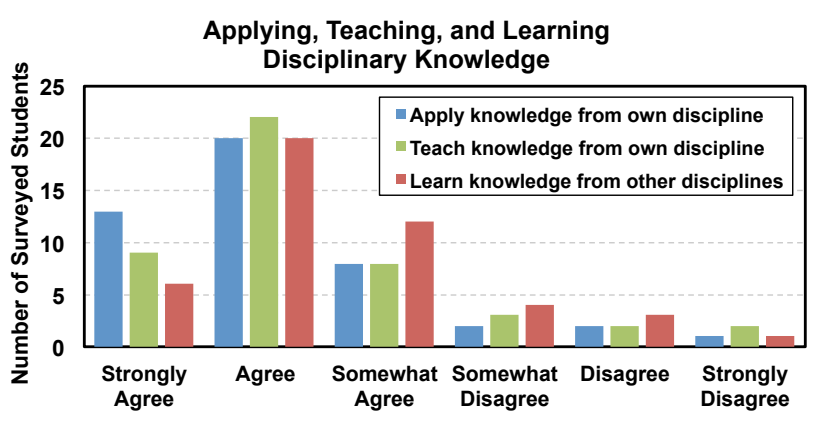

Fig. 4. Degree of disciplinary knowledge application, teaching, and learning within design teams

\section{RESULTS AND DISCUSSION}

The following section highlights the trends observed in the quantitative survey data regarding the transfer of knowledge in multidisciplinary design teams. In order to develop a broader understanding of the technical and nontechnical factors that affect multidisciplinary design, evidence from the qualitative interviews is used to provide complimentary insights that may not have been captured through the statistical survey data.

\subsection{Knowledge Transfer and Application}

Multidisciplinary design teams must share knowledge across disciplinary boundaries in order to fully integrate discipline-specific design modules. As shown in Fig. 1, this is accomplished by applying knowledge within a specific discipline, while also teaching and learning select concepts and principles from other project disciplines. The survey and interview results indicate that students designing a module in their own discipline had to learn just enough from another discipline to enable integration, while students working on design modules outside of their own discipline had to learn new concepts extensively.

As shown in Fig. 4, the majority of students agreed that cross-disciplinary knowledge transfer was required for their project. This result is supported by interview evidence, where students identified that they learned new disciplinary concepts, both independently and from other team members, to develop design modules both within and outside their own discipline. As one Industrial Engineering student who taught "user interface design and usability" to his teammates explained: "I definitely tried to make it very clear why we had to do certain things, especially around response time. [...] Really walk them through from a new user's point of view, and I think they got it. [... It helped] motivate them [... and they] did catch [things] on their own after that. [...] I learned a lot about Android development, how the programs are structured, how classes work, how the application starts, how you communicate between Android devices. [...] I learned a lot about what you can and can't do, and how hard it is." By applying this knowledge in design and workarounds, the student explained that he learned "not how to write the code itself, but how to build the solution." Such a case shows how students are able to teach key concepts from a particular discipline such that other team members can effectively integrate the knowledge into their work.

\subsection{Disciplinary Skills and Project Requirements}

Each member of a multidisciplinary team contributes a unique set of skills, which influence how the team applies, teaches, and learns discipline-specific knowledge. As shown in Fig. 5, the general trend indicates that design teams primarily applied knowledge from their own disciplines, with teaching and learning varying according to the nature of the sub-discipline. Survey results presented in Fig. 6 indicate that $71 \%$ of students were part of a team where team members had the required skills and disciplinary knowledge for their project. In these cases, there is a strong correlation to how well students applied, taught, and learned disciplinary knowledge. However, the survey results in Fig. 6 show that even teams that did not have the required skills for their project were still able to apply, teach, and learn discipline-specific knowledge. This is evident by the binodal pattern, which appears in each of the categories in Fig. 6.

At least $88 \%$ of students whose team disciplines matched the project requirements somewhat agreed, agreed, or strongly agreed that they were able to directly

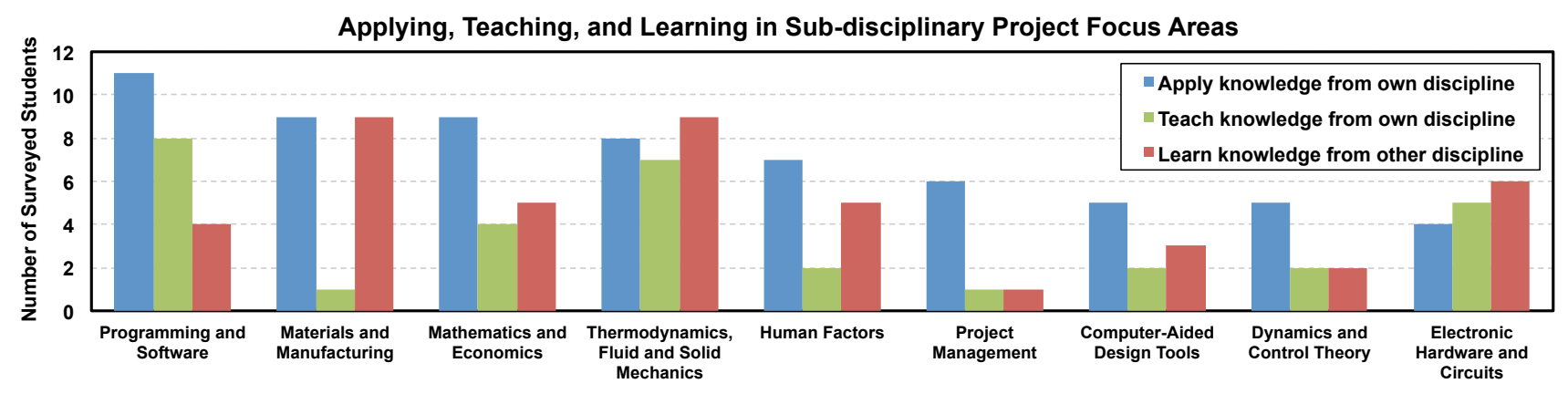

Fig. 5. Sub-disciplinary project focus areas for knowledge application/teaching/learning within teams 


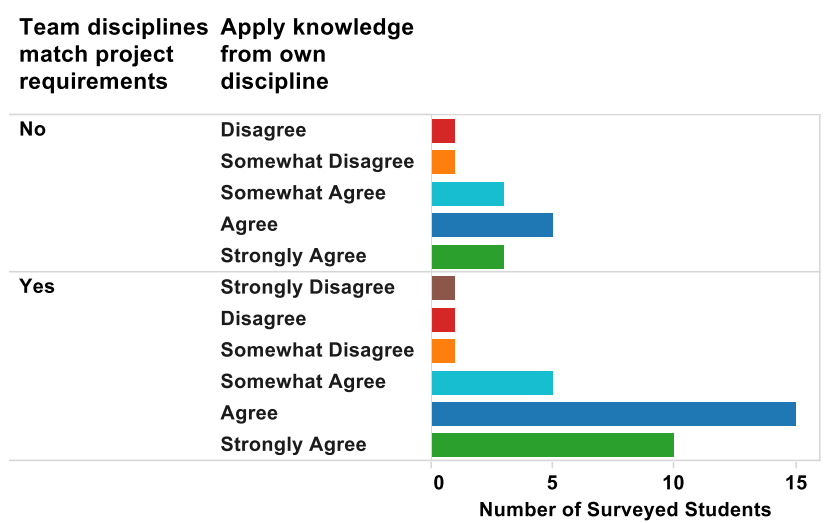

(a)

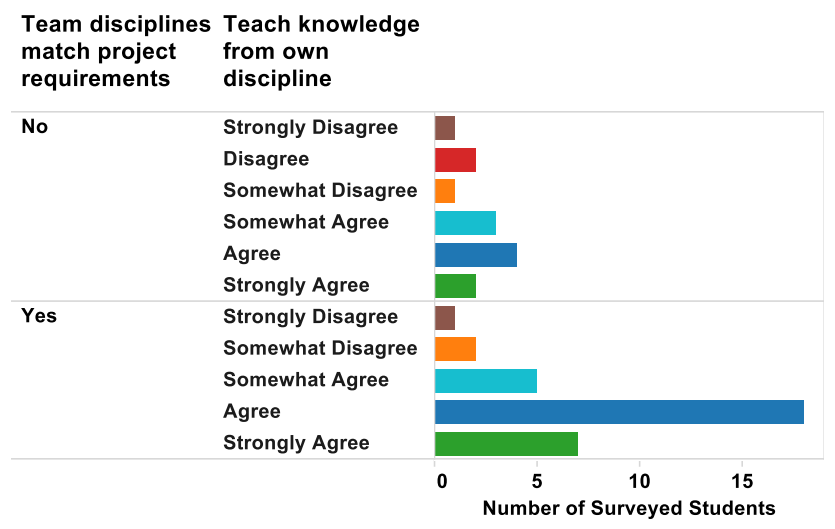

(b)

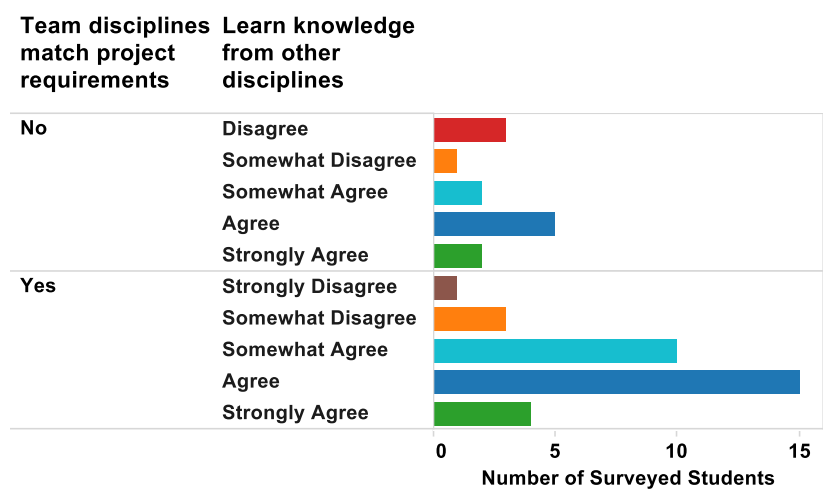

(c)

Fig. 6. The impact of team skills on the transfer of disciplinary knowledge

apply, teach, and learn disciplinary knowledge. The interviews provided some insight into the depth of that knowledge sharing. Many students explained that they did not acquire in-depth knowledge about their team members' fields, but rather obtained just a high-level overview. For example, a Materials Science Engineering student explained: "It's not like I understood the nifty details as they would have in their heads, but I understood how the systems interacted with each other, how given all these small components, how they came together." This example illustrates how teams that already possessed the required skills were able to directly share just enough knowledge between members to enable integration.

Although some teams did not initially possess the skills and disciplinary knowledge required for their project, at least $69 \%$ of students in this category somewhat agreed, agreed, or strongly agreed that they were nevertheless able to apply, teach, and learn disciplinary knowledge. In an interview, a Chemical Engineering student explained that: "I did learn on an individual basis. There was definitely a business side to the project that I had to learn new skills to understand, to be able to analyze for a cost-benefit analysis purpose. So we did learn a couple of new skills, but I just didn't necessarily learn it from their disciplines and the tools that they had." This example illustrates the scenario where students must first acquire an in-depth understanding of a new focus area or discipline, in order to apply that knowledge to solve the design problem.

\subsection{Impact of Open Communication}

Lastly, this section explores how team communication and feedback affect the perceived value of unique member skills and likelihood of risk-taking. Free and open communication within a team creates an atmosphere for collaboration, where members are welcome to express new ideas and take risks, with the support of constructive feedback from other team members. This phenomenon is captured by the survey results presented in Fig. 7, where there is a strong correlation between risk-taking and value of unique skills in teams that had open communication and feedback among team members.

The interviews served to provide further insights into how teams leveraged the unique disciplinary skills among members, and how the value of these skills encouraged risk-taking. For instance, a Mechanical Engineering student working on a Financial Engineering project explained: "I taught some of the forecasting techniques we used in the project and the guys from the Finance option [...] referred me to the algorithm [they] learned and proposed to use. [...] There was inter-teaching [...] For example, my partner devised a trading strategy and it was his job to sit down and explain to us what he wrote down, what his theories were, what he was applying, and why he was applying it. [...] That's the whole point of different disciplines." In fact, some students even observed that sharing these multidisciplinary skills led to more creative design solutions. For example, another Mechanical Engineering student explained: "The design we have, we could theoretically have designed with just Mechanical. Having the confidence that we could actually go through and make it was influenced by the fact that we had an ECE member on our team. The knowledge that he was able to bring with problems that would arise on the computer side, that arise from integrating the hardware 
and software together, allowed us to go forward in this project with the confidence that we could actually make it, versus if we were just Mechanical, we would have a huge section of knowledge missing that we would have to learn in addition to all the time that we already put in, which may have been too much, or just have to stop and scale back [...] to something at a lower level, not have gone for such an aggressive project." As described by the interview participants, the knowledge sharing between team members from different disciplines actually instilled confidence in the team to take risks and go further with the project.

The interviews also revealed other key aspects of multidisciplinary team dynamics, which were not explicitly investigated in the survey. Specifically, we learned that some of the non-technical challenges that hinder the transfer of knowledge and affect team dynamics include: (1) lack of motivation, (2) unbalanced expectations, (3) unbalanced workloads, and (4) lack of trust. We observed that teams that encouraged open communication and provided adequate feedback were more likely to build trust among members, sustain a high level of motivation throughout the duration of the project, and share knowledge across disciplines.

\section{CONCLUSION}

The results presented in this preliminary study offer some insight into the potential correlations that affect team dynamics and how teams share knowledge across disciplines in a multidisciplinary capstone design course. Although the findings are not definitive based on the limited data set collected from just a single course in one academic year, several key areas for further investigation have been identified. This study has revealed that crossdisciplinary teaching and learning between students in multidisciplinary design teams helps fill knowledge gaps to enable design integration, and seems to provide students with the confidence to take risks and apply knowledge outside their own discipline. Through open communication and feedback, students are able to build strong team dynamics to tackle complex engineering design problems with real world applications. This finding may have immediate implications for instruction and guidance provided to teams through the course of the project.

The early nature of this study has identified several areas for future work, particularly regarding the way students teach, learn, and then apply knowledge, and how specific team communication practices lead to successful multidisciplinary design. Future studies may choose to examine the impact of in-depth versus superficial learning approaches within design teams, as well as the nontechnical challenges that were identified during our interviews, including motivation, workload, expectations, and trust. A more comprehensive understanding of prior

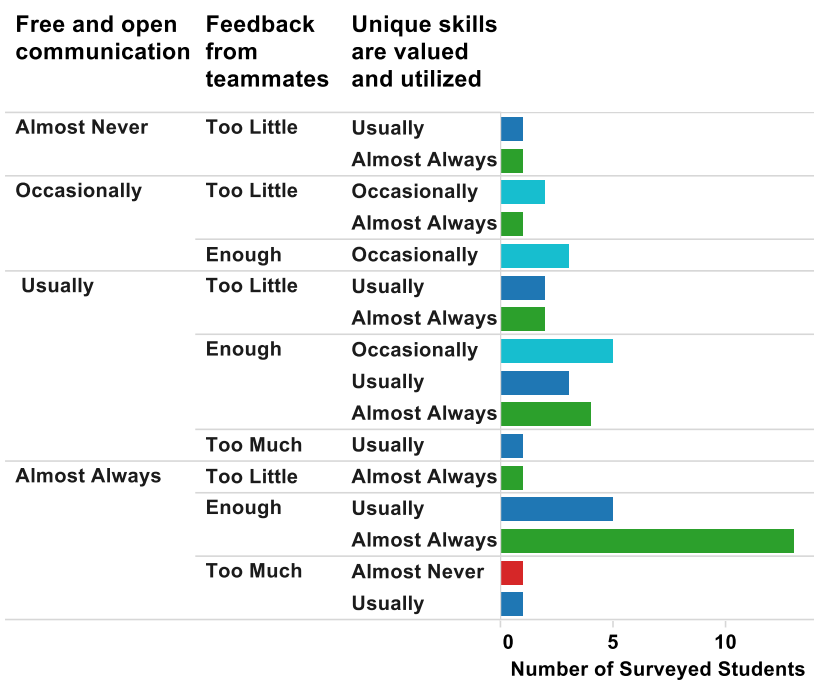

(a)

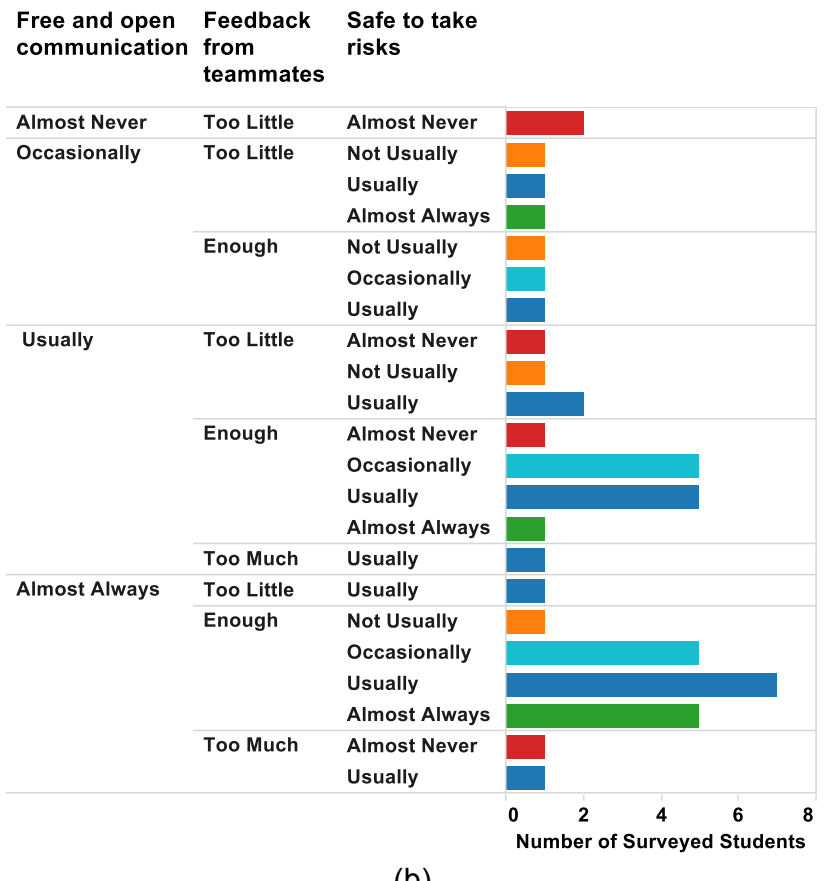

(b)

Fig. 7. The impact of team communication and feedback on the (a) value of team skills and (b) risk taking

student design team experience from extracurricular activities and internships may also lead to further insights on how teams communicate across disciplines. Some of these insights can be captured by closely monitoring a team's activities for the duration of their design project, or through more focused interviews with individual team members and the team as a whole. Quantitative metrics and measures of success can help track how teams formulate their project requirements, and refine them throughout the development of their design. Moreover, it 
would be valuable to examine the team formation processes in multidisciplinary teams, and how the formal definition of roles, responsibilities, and expectations affect team dynamics, motivation, and innovation. Lastly, future studies could also follow up on the successes of multidisciplinary capstone projects to understand how multidisciplinary teams innovate, and whether their innovations exceed those of monodisciplinary teams, from a client or supervisor perspective. Running similar studies at other institutions would provide a more holistic view of how communication impacts multidisciplinary design, and how capstone design courses can evolve within the engineering curriculum to best prepare students for real world engineering challenges.

\section{Acknowledgements}

The authors would like to thank the Natural Sciences and Engineering Research Council of Canada (NSERC) for funding this research through the Chairs in Design Engineering (CDE) grant. This research was also supported by the Engineering Communication Program (ECP) within the Faculty of Applied Science and Engineering at the University of Toronto.

\section{References}

[1] David S. Strong, "An Approach for Improving Design and Innovation Skills in Engineering Education: The Multidisciplinary Design Stream," International Journal of Engineering Education, vol. 28, no. 2, pp. 339-348, 2012.

[2] Natalie Hotaling, Barbara Burks Fasse, Lewis F. Bost, Christopher D. Herman and Craig R. Forest, "A Quantitative Analysis of the Effects of a Multidisciplinary Engineering Capstone Design Course," Journal of Engineering Education, vol. 101, no. 4, pp. 630-656, 2012.

[3] Kamran Behdinan, Remon Pop-Iliev and Jason Foster, "What constitutes a multidisciplinary capstone design course? Best practices, successes and challenges," in Proc. 2014 Canadian Engineering Education Association (CEEA14) Conf. (Canmore, AB; June 8-11, 2014), 5 pp., 2014.

[4] Jay Goldberg, Vikram Cariapa, George Corliss and Kate Kaiser, "Benefits of Industry Involvement in Multidisciplinary Capstone Design Courses," International Journal of Engineering Education, vol. 30, no. 1, pp. 6 - 13, 2014.

[5] Kristen Gruenther, Reid Bailey, Jennifer Wilson, Charles Plucker and Hiba Hashmi, "The influence of prior industry experience and multidisciplinary teamwork on student design learning in a capstone design course," Design Studies, vol. 30, pp. 721-736, 2009.

[6] Andrea I. Schäfer and Bryce S. Richards, "From concept to commercialisation: student learning in a sustainable engineering innovation project," European Journal of Engineering Education, vol. 32, no. 2, pp. 143-165, 2007.

[7] Jessica Mesmer-Magnus and Leslie DeChurch, "Information sharing and team performance: A metaanalysis," Journal of Applied Psychology, vol. 94, pp. 535546, 2009.

[8] Tobias Greitemeyer, Stefan Schulz-Hardt, Felix C. Brodbeck and Dieter Frey, "Information sampling and group decision making: The effects of an advocacy decision procedure and task experience," Journal of Experimental Psychology: Applied, vol. 12, pp. 31-42, 2006.

[9] Garold Stasser and William Titus, "Pooling of unshared information in group decision making: Biased information sampling during group discussion," Journal of Personality and Social Psychology, vol. 48, pp. 1467-1478, 1985.

[10] Susannah B.F. Paletz, "Multidisciplinary Teamwork and Big Data," in HCBDR14 (Raleigh, NC; April 1-3, 2014).

[11] Daria E. Topousis, Cornelius J. Dennehy and Kenneth L. Lebsock, "Nasa's Experiences Enabling the Capture and Sharing of Technical Expertise Through Communities of Practice," Acta Astronautica, vol. 81, pp. 499-511, 2012.

[12] Randolph Hutchison, Courtney Faber, Lisa Benson, Adam Kim and John D. DesJardins, "Assessing Student Knowledge Transfer During Group Work," in Proc. Frontiers in Education Conf. 2013 IEEE (Oklahoma City, OK; October 23-26, 2013), 7 pp., 2013.

[13] Julie Dyke Ford, "Knowledge Transfer Across Disciplines Tracking Rhetorical Strategies From a Technical Classroom to an Engineering Classroom," IEEE Transactions on Professional Communication, vol. 47, no. 4, pp. 301-315, 2004. 